\title{
JURNAL CERIA
}

ISSN : 2614-6347 (Print) 2614-4107 (Online)

Vol.1 1 No.3 1 Mei 2018

UPAYA GURU DALAM MENINGKATKAN KEMAMPUAN GERAK

LOKOMOTOR MELALUI PERMAINAN TRADISIONAL BOI-BOIAN PADA

KELOMPOK B DI TK ISLAM RUMAH ILMU CIMAHI

\author{
Sahanah $^{1}$, Ema Aprianti ${ }^{2}$ \\ ${ }^{1}$ Tk Islam Rumah Ilmu, Cimahi \\ ${ }^{2}$ IKIP Siliwangi Bandung, Jl. Terusan Jenderal Sudirma \\ ${ }^{1}$ sahanahrumahilmu@gmail.com, ${ }^{2}$ ema-aprianti@ikipsiliwangi.ac.id
}

\begin{abstract}
The study was conducted based on the findings of the problem that tekait with rough motor skills in group B in Islamic Kindergarten of Rumah Ilmu Cimahi. Problems that exist in the Islamic Kindergarten House Science is almost no land to play, where the physical movement of children requires a wide range of movement. Also habituation of children who prefer to watch television and play dadget. Traditional boi-boian games can support rough motor stimulation in children. The boi-boian game activities conducted in this research succeeded in assisting one of these obstacles. In the process performed can be seen that children who had a poor motor skills are less good, began to do some rough motor activities better. Based on the background of the above research shows the need for efforts in improving the abilities of rough motor physical children. The formulation of the problem in this research is "Is Through Boi-Boian Games in Children Can Improve the Ability of Motoric Motorcycle of Children in Group B in Islamic Kindergarten of House of Science?" This research aims to increase the rough motor skills of children through traditional boi-boian game. The method used in this research is qualitative method with analytical descriptive. Research data collected by using instrument in the form of interview and observation guideline. The results obtained are very satisfactory.
\end{abstract}

Keywords: Teacher Effort, Rough Motoric, Traditional Games

\section{Abstrak}

Penelitian di lakukan berdasarkan temuan masalah yang tekait dengan kemampuan fisik motorik kasar pada kelompok B di TK Islam Rumah Ilmu Cimahi. Masalah yang ada pada lingkungan TK Islam Rumah Ilmu adalah hampir sudah tidak ada lahan untuk bermain, dimana gerak fisik anak membutuhkan tempat yang luas. Juga pembiasaan anak yang lebih suka menonton televisi dan bermain dadget. Permainan tradisional boi-boian bisa menunjang stimulasi motorik kasar pada anak. Kegiatan permainan boi-boian yang dilaksanakan pada observasi ini berhasil membantu salah satu kendala tersebut. Dalam proses yang dilakukan dapat dilihat bahwa anak yang tadinya memiliki kemampuan gerak lokomotor yang kurang baik, mulai bisa melakukan beberapa kegiatan motorik kasar dengan lebih baik. Berdasarkan latar belakang penelitian diatas menunjukan perlu adanya upaya dalam menambah kemampuan gerak lokomotor anak. Adapun permasalahannya ini adalah "Apakah Melalui Permainan Boi-Boian pada Anak bisa Menambah Kemampuan Gerak LokomotorSiswa pada Kelas 0 Besar di TK Islam Rumah Ilmu?'Penelitian ini bertujuan untuk menambah kemampuan gerak lokomotor anak melalui permainan tradisional boi-boian. Metode yang dipilih dalam observasi ini adalah metode kualitatif dengan deskriptik analistik. Data penelitian dikumpulkan dengan menggunakan instrument berupa pedoman wawancara dan pedoman observasi. Hasil yang diperoleh sangat memuaskan. 


\section{JURNAL CERIA}

ISSN : 2614-6347 (Print) 2614-4107 (Online)

Vol.1 1 No.3 1 Mei 2018

Kata Kunci: Upaya guru, Motorik Kasar, Permainan tradisional

How to Cite: Sanahah., \&Aprianti, E. (2018). UPAYA GURU DALAM MENINGKATKAN

KEMAMPUAN GERAK LOKOMOTOR MELALUI PERMAINAN TRADISIONAL BOI-BOIAN PADA

KELOMPOK B DI TK ISLAM RUMAH ILMU CIMAHI. Ceria, 1 (3), 24-29.

\section{PENDAHULUAN}

Untuk membina dan menambah bakat anak bangsa dapat diupayakan melalui pembangunan di berbagai bidang yang didukung oleh atmosfer masyarakat belajar. Anak taman kanakkanak kedudukannya sebagai generasi penerus bangsa perlu mendapatkan posisi yang strategis dalam pembangunan.

Pertumbuhan dan perkembangan pada anakanak sangat dipengaruhi oleh banyak faktor, diantarnya lingkungan, keluarga, sekolah, masyarakat, fasilitas genetika dan status gizi.

Pertumbuhan (growth) menunjukan pada perubahan kuantitas dalam ukuran, pada tubuh. Perkembangan (development) menggambar perubahan fungsi. Toto Cholik Mutohir(Samsudin, 2008)Perkembangan motorik berkaitan dengan kematangan mekanisme otot, syaraf yang memberikan penampilan progresif di dalam keterampilan motorik. Cratty(Samsudin, 2008).

Zulkifli menjelaskan, bahwa yang dimaksud dengan motorik adalah hal-hal yang ada hubungannnya dengan gerakan-gerakan tubuh. Selanjutnya dijelaskannya bahwa dalam perkembangan motorik terdapat tiga unsur yang menentukannya yaitu otot, saraf dan otak. Ketiga unsur ini melaksanakan masing-masing perannya secara interaksi positif

Menurut James Dananjaja(Keen, 2012. Hlm. 13), permainan tradisional adalah salah satu bentuk yang berupa permainan anak-anak, yang beredar secara lisan di antara anggota kolektif tertentu, berbentuk tradisional dan diwarisis turun-temurun, serta banyak memilikipilihan. Permainan zaman dahulu tidak lain adalah kegiatan yang diatur oleh suatu peraturan permainan yang merupakan pewarisan dari generasi terdahulu yang dilakukan manusia (anak-anak) dengan tujuan mendapatkan kegembiraan. Salah satu permainan tradisional yaitu permainan boi-boian. Permainan boi- boianpopular pula dengan sebutan gebokan. Banyaknyaanggota dalam permainan ini sedikitnya 3 anak. Akan tetapi, makin banyak anak yang ikut bermain, permainan akan makin lebih seru.

Konsep Dasar Pendidikan Pra Sekolah

Hakikat Anak Pra Sekolah

Anak pra sekolah adalah sosok individu yang sedang menjalani suatu proses perkembangan dengan pesat dan fundamental bagi kehidupan selanjutnya. Anak usia dini rentang usia 0-8 tahun (http: www.naeyc.org). Pada masa ini proses pertumbuhan dan perkembangan dalam aspek sedang mengalami masa yang cepat dalam rentang perkembangan manusia Berk (Sujiono, 2012. Hlm. 18).

Tujuan, Fungsi Pendidikan Anak Pra Sekolah

Pendidikan nasional berperan mengembangkan kemampuan dan membentuk watak serta peradaban bangsa yang punya nilai luhur dalam rangka mencerdaskan kehidupan bangsa, bertujuan untuk berkembangnya keahlian peseta didik agar menjadi manusia yang berjiwa pancasila (UU RI No. 20/2003 BAB II Pasal 3)

1. Teori Perkembangan Anak Pra Sekolah

Anak pra sekolah berada dalam masa keemasan di sepanjang rentang usia perkembangan manusia, Montessori (Sujiono, 2012. Hlm. 10-11)menjelaskan bahwa masa ini merupakan periode senstif (sensitive periods), selama usia inilah anak secara khusus mudah menerima rangsangan dari lingkungannya. Pada masa ini anak siap melakukan berbagai aktifitasuntuk memonopoli lingkungannnya. Pada masa peka inilah terjadi pematangan fungsifungsi fisik dan psikis sehingga anak siap menerima dan membuat semua tugas-tugas perkembangan yang diharapkan muncul pada pola perilakunya sehari-hari Hainstok (Samsudin, 2008. Hlm. 34)

Teori Pertumbuhan dan Perkembangan

Berdasarkan teori perkembangan anak, diyakini bahwa setiap individu lahir dengan lebih 


\section{JURNAL CERIA}

ISSN : 2614-6347 (Print) 2614-4107 (Online)

Vol.1」No.3」Mei 2018

dari beberapa bakat. Bakat tersebut bersifat potensial dan ibaratnya belum muncul di atas permukaan air. Anak memerlukan pendidikan yang sesuai dengan perkembangannya dengan cara memperluas lingkungan bermainnya. Untuk itu kita wajib memberi peluang kepada anak untuk menyatakan diri, berekspresi, berkreatif, berkreasi.

\section{Konsep Upaya/Peran Guru}

Peran Guru Dalam Pendidikan Anak Usia TK adalah suatu proses perubahan yang menyangkut tingkah laku atau kejiwaan. Dalam psikologi belajar, proses berarti cara-cara atau langkah-langkah khusus yang dengannya beberapa perubahan ditimbulkan hingga tercapainya hasil-hasil tertentu. Jadi dapat disimpulkan proses belajar adalah sebagai tahapan perubahan perilaku aspek perkembangan yang terjadi dalam diri siswa. Perubahan tersebut bersifat positif dalam arti berujung pada arah yang lebih baik daripada keadaan sebelumnya. Guru adalah orang pertama yang langsung berhubungan dengan anak dalam upaya proses pembelajaran, upaya guru itu tidak terlepas dari adanya kurikulum.

Konsep Perkembangan Lokomotor Pada Usia Dini

Pengertian Fisik Motorik

Setiap anak ingin bergerak dan ingin menggunakan fisiknya secara bebas dengan menggunakan anggota tubuhnya. Setiap gerakan anak melibatkan tiga unsur penting, yaitu : otot, otak dan syaraf. Jika salah satu dari ketiga unsur penting itu tidak berfungsi dengan baik maka gerakan yang dihasilkan juga tidak akan bermakna atau tidak terjadi gerakan sama sekali.

Muhibbin, motor dapat pula dipahami sebagai segala keadaan yang meningkatkan atau menghasilkan stimulasi/rangsangan kegiatan organ-organ fisik.

Howe yang dikutip oleh Muhibbin mencontohkan bahwa aktivitas motorik seperti melakukan polapola gerakan yang cukup dan terkoordinasi melibatkan proses mental yang sangat kompleks.

Dasar Perkembangan Motorik anak Prasekolah (TK)

Pengertian Perkembangan anak TK
Perubahan kemampuan motorik dari bayi sampai dewasa yang memasukan berbagai aspek prilaku dan kemampuan gerak.

\section{Prinsip Perkembangan Motorik TK}

Suatu perubahan fisik dan psikis sesuai dengan masa pertumbuhannya. Perkembangan gerak anak sangat dipengaruhi oleh gizi, status kesehatan dan perlakuan gerak anak yang sesuai dengan masa perkembangan.

\section{Pandangan dalam Perkembangan Gerak Anak \\ Pandangan yang diperoleh dari} perkembangan pada anak prasekolah antara lain mendapatkan pengalaman yang berarti, hak dan kesempatan berkreativitas, kesesuaian jiwa dan raga, serta mampu berfungsi menjadi dirinya sendiri.

\section{Tujuan dan Manfaat Perkembangan Motorik TK}

Penguasaan keterampilan yang tergambar dalam keahlian menbereskan tugas motorik tertentu. Kualitas motorik bisa dilihat dari seberapa jauh anak tersebut mampu memperlihatkan tugas motorik yang diberikan dengan tingkat ketercapaian tertentu. Jika tingkat keberhasilan dalam melaksanakan motorik tinggi, berarti motorik yang dilaksanakan cepat dan tepat

Faktor-faktor yang mempengaruhi Perkembangan Fisik anak TK

Ada beberapa faktor yang mempengaruhi perkembangan fisik anak, diantaranya adalah : faktor keluarga, gizi, emosional, jenis kelamin, status sosial emosional. Kesehatan, pengaruh postur.

Perkembangan motorik kasar pada anak TK

Perkembangan motorik ialah perkembangan kemampuan pengendalian tubuh melalui pusar syaraf, urat syaraf dan otot-otot yang terkoordinasi Bahan Ajar PAUD 2011(Jumiatin, 2011: 14). Motorik kasar merupakan perkembangan fisik berupa koordinasi gerakan tubuh, seperti bergeser, berjinjit, berjingkrak, bergantung, melempar dan menangkap serta menjaga keseimbangan. Kegiatan ini diperlukan untuk meningkatkan keahlianpenyelarasan gerakan gerak lokomotor. Gerakan motorik kasar 


\section{JURNAL CERIA}

ISSN : 2614-6347 (Print) 2614-4107 (Online)

Vol.1 1 No.3 1 Mei 2018

menggunakan otot-otot kasar seperti berlari, memanjat, melompat, melempar dan sebagainya. Kemampuan motorik kasar sangat dibutuhkan oleh anak usia dini untuk kegiatan permainan dengan teman-teman.

\section{Konsep Permainan Tradisional}

Konsep Permainan

Menurut Hans Daeng permainan adalah bagian mutlak dari kehidupan anak dan permainan merupakan bagian integral dari proses pembentukan kepribadian anak Hans Daeng, 2009 . Permainan diartikan sebagai aktifitas bermain yang dilakukan dalam rangka mencari kebahagian dan kepuasan, namun diukur pencarian menang atau kalah (Andang Ismail,2009: 26).

Sedangkan yang dimaksud dengan tradisional adalah apa-apa yang dikatakankan atau diwariskan secara turun temurun dari orang terdahulu atau nenek moyang. (Atik Soepandi, 1990: 12).

\section{METODE PENELITIAN}

Penelitian kualitatif pada hakikatnya ialah mengobservasiindividu dalam lingkungan hidupnya, bergelut dengan mereka, berusaha mengerti bahasa dan tafsiran mereka tentang dunia sekitarnya Nasution (Sugiyono, 2010. Hlm. $5)$.

Metode yang dipergunakan oleh peneliti yaitu metode kualitatif. Dengan deskriftif analisa menggunakan tekhnik observasi diartikan sebagai penelitian pencatatan secara sistematika terhadap gejala tampak oleh peneliti Margono, (Sugiyono, 2010. Hlm. 158)

Metode Penelitian kualitatif adalah metode penelitian yang berlandaskan pada filsafat postpositivisme, digunakan untuk meneliti pada situasi obyek yang alamiah, sebagai lawannya adalah eksperimen) dimana penelitian adalah sebagai alat kunci, tehnik pengumpulan data dilaksanakan secara tringualisasi (gabungan), analisis data bersifat induktif/kualitatif dan hasil penelitian kualitatif lebih menekankan makna pada generilisasi (Sugiyono, 2016. Hlm. 15)

Teknik pengambilan data yang dilaksanakan dalam pengamatan ini sebagai berikut :
1. Observasi

2. Wawancara

3. Studi Dokumentasi

4. Studi Literatur

Data mentah yang telah diperoleh oleh peneliti tidak berfungsi jika tidak diolah. Pengolahan data merupakan bagian yang sangat penting dalam metode ilmiah. Karena dengan pengolahan data, data tersebut dapat bermakna yang berfungsi dalam menangani masalah pengamatan.

Subyek penelitian adalah berbagai karakteristik yang terlibat dalam pengenalan permainan tradisional boi-boian yang terdiri dari 13 siswa dan satu pendidik.Lokasi penelitian dilaksanakan di TK Islam Rumah Ilmu Kelurahan Utama Kecamatan Cimahi Selatan. Adapun subjek penelitian adalah siswa-siswi kelompok B1 TK Islam Rumah Ilmu Cimahi pada semester II tahun ajaran 2017-2018. Jumlah siswa 14 (empat belas) orang, yang terdiri dari delapananak laki-laki dan lima orang perempuan. Dan yang diteliti lima anak dengan rincian dua anak permepuan dan tiga anak laki-laki.

Langkah-Langkah Penelitian

Menurut (Moleong, 2002. Hlm. 127)bahwa tahapan yang dilaksanakan dalam pengamatan kali ini ada empat tahap, yaitu:

1. Tahap Pra Lapangan

2. Tahap Pelaksanaan

3. Tahap Analisis Data

4. Tahap Pelaporan

\section{HASIL DAN PEMBAHASAN}

Berdasarkan hasil observasi yang dilakukan peneliti terhadap anak kelas nol besar di TK Islam Rumah Ilmu, kondisi umum lokomotor anak sudah cukup baik. Berdasarkan hasil wawancara dengan guru kelas kendala yang dialami anak dalam mengembangkan mengoptimalkan kemampuan lokomotornya adalah pembiasaan dirumah yang kurang menitik beratkan pada aspek perkembangan lokomotor pada anak. Berdasarkan penuturan guru kondisi anak di tempat tinggalnya yang lebih banyak diam, bermain game melalui gadget, dan menonton televisi dengan durasi yang cukup lama (lebih dari dua jam sehari) menjadi salah satu faktor kurangnya kemampuan lokomotor anak. 


\section{JURNAL CERIA}

ISSN : 2614-6347 (Print) 2614-4107 (Online)

Vol.1 1 No.3 1 Mei 2018

Kendala lain adalah karena hampir sudah sudah tidak ada lahan untuk bermain, dimana gerak fisik memerlukan tempat yang lebar.

Permainan Boi-Boian Sebagai Upaya Meningkatkan Kemampuan Fisik Motorik Kasar Anak

Pada pelaksanaan penelitian, peneliti memulai dengan melakukan pengenalan terhadap permainan boi-boian secara klasikal pada anak. Pada kegiatan pertama, peneliti hanya memberikan contoh cara bermain dan mengobservasi kemampuan motorik kasar anak. Pada kegiatan kedua, peneliti mulai memberikan intervensi dengan memperbaiki gerakan anak agar bisa melakukan kegiatan secara optimal.Berdasarkan hasil observasi pada anak dan wawancara terhadap guru, dapat disimpulkan bahwa permainan tradisional boi-boian bisa menunjang stimulasi motorik kasar pada anak.

Temuan Hasil Penelitian

Upaya Guru Dalam Merencanakan LangkahLangkah Untuk Mengoptimalkan Kemampuan Gerak Lokomotor Anak Melalui Permainan Tradisional Boi-Boian.

Guru membuat program kegiatan yang sesuai dengan tingkat perkembangan anak. Setiap awal tahun pembelajaran guru memberikan program kegiatan semester kepada kepala sekolah, kemudian pihak sekolah memasukan rancangan program tersebut kedalam rencana program semester. Dari hasil wawancara tersebut diperoleh data bahwa program kegiatan permainan tradisional boi-boian diberikan satu kali dalam satu tahun yaitu pada pertengahan semester 2 .

Pelaksanaan/ Penerapan Permainan Tradisional Boi-Boian Untuk Mengoptimalkan Kemampuan Lokomotor Pada Anak

Berdasarkan hasil wawancara pada guru kelas nol besar didapatkan hasil bahwa pada umumnya kemampuan lokomotor anak kelompok B berkembang dengan baik. Anak-anak bisa mengikuti tahapan dalam melakukan sebuah kegiatan. Adapun kegiatan yang bisa dilakukan di sekolah adalah kegiatan yang bisa melatih ketangkasan, keseimbangan dan antusias, misalnya kegiatan berlari.

Hasil Obsevasi Kegiatan Motorik Kasar Anak Melalui Permainan Tradisional Boi-Boian

Adapun indikator yang diobservasi adalah: Anak mengenal permainan, Anak mengenal permainan, Anak melakukan kegiatan yang menunjukan anak mampu melakukan permainan fisik dengan aturan, Anak menggulingkan objek menyusuri lantai dengan tangan kanan, Anak menyusun pecahan genting, Anak melemparkan objek/bola plastik kesasaran dengan satu tangan, Berlari dari satu tempat ke tempat yang lain, Anak mengikuti permainan dari awal sampai akhir.

a. Berdasarkan data hasil observasi dapat dilihat bahwa pada dasarnya sebagian anak di kelompok B belum bisa melakukan gerakan pada kegiatan permainan boi-boian dengan baik. Terlihat pada anak dikelompok B belum bisa menggelindingkan bola ke pecahan genting, melempar bola ke sasaran dengan baik. Juga untuk anak yang menjaga pecahan genting, masih belum mengerti dalam mencari sasaran lawan.

b. Berdasarkan data hasil observasi dapat dilihat bahwa pada dasarnya sebagian anak di kelompok B sudah bisa melakukan gerakan pada kegiatan permainan boi-boian dengan baik. Terlihat pada anak dikelompok B sudah bisa menggelindingkan bola ke pecahan genting karena agak sulit dilakukan, melempar bola ke sasaran dengan baik. Juga untuk anak yang menjaga pecahan genting, sudah mulai mengerti dalam mencari sasaran lawan.

c. Berdasarkan data hasil observasi diatas dapat disimpulkan bahwa anak di kelompok B sudah bisa melakukan gerakan pada kegiatan permainan boi-boian dengan baik. Terlihat pada anak di kelompok B sudah bisa menggelindingkan bola ke pecahan genting, melempar bola ke sasaran dengan baik, berlari, dan bisa mengikuti aturan permainan dengan baik.

\section{KESIMPULAN}

Berdasarkan hasil penelitian, dapat disimpulkan bahwa kemampuan lokomotor anak yang kurang baik bisa dipicu oleh pembiasaan 


\section{JURNAL CERIA}

ISSN : 2614-6347 (Print) 2614-4107 (Online)

Vol.1 | No.3 | Mei 2018

anak berdiam diri sambil bermain dadget maupun menonton televisi. Kendala lain adalah karena hampir sudah tidak ada lahan untuk bermain, dimana gerak fisik memerlukan tempat yang lebar. Oleh karena itu anak membutuhkan stimulus, mengingat pentingnya kemampuan gerak lokomotor anak bagi perkembangan selanjutnya. Kegiatan permainan boi-boian yang dilaksanakan dalam pengamatan ini berhasil membantu salah satu kendala tersebut. Dalam proses yang dilakukan dapat dilihat bahwa anak yang tadinya memiliki kemampuan gerak lokomotor yang sedikit tidak baik, mulai bisa melakukan beberapa kegiatan motorik kasar dengan lebih baik.

Permainan tradisional boi-boian bisa menjadi salah satu alternatife kegiatan motorik kasar yang menyenangkan bagi anak. Karena permainan ini sungguh menarik, sehingga anak bisa melakukannya dengan riang dan di saat yang bersamaan anak mendapatkan stimulasi motorik kasar.

\section{DAFTAR PUSTAKA}

Keen, A. (2012). Mengoptimalkan Tumbuh
Kembang Anak Melalui Permainan Tradisional. Jakarta: Javalitera.

Moleong, J. L. (2002). Metode Penelitian Kualitatif. Bandung. PT Remaja Rosda Karya.

Samsudin. (2008). Pembelajaran motorik Di Taman Kanak-Kanak. Prenada Media Group.

Sugiyono. (2010). Metode Penelitian Pendidikan. Bandung: Alfabeta.

Sugiyono. (2016). Metode penelitian kuantitatif dan kualitatif. Bandung: Alfabeta.

Sujiono, Y. N. (2012). Konsep Dasar Pendidikan Anak Usia Dini. Jakarta: Indeks. 